\title{
Increased malaria transmission around irrigation schemes in Ethiopia and the potential of canal water management for malaria vector control
}

\author{
Solomon Kibret ${ }^{1 *}$, G Glenn Wilson ${ }^{1}$, Habte Tekie ${ }^{2}$ and Beyene Petros ${ }^{3}$
}

\begin{abstract}
Background: Irrigation schemes have been blamed for the increase in malaria in many parts of sub-Saharan Africa. However, proper water management could help mitigate malaria around irrigation schemes in this region. This study investigates the link between irrigation and malaria in Central Ethiopia.

Methods: Larval and adult mosquitoes were collected fortnightly between November 2009 and October 2010 from two irrigated and two non-irrigated (control) villages in the Ziway area, Central Ethiopia. Daily canal water releases were recorded during the study period and bi-weekly correlation analysis was done to determine relationships between canal water releases and larval/adult vector densities. Blood meal sources (bovine vs human) and malaria sporozoite infection were tested using enzyme-linked immunosorbent assay (ELISA). Monthly malaria data were also collected from central health centre of the study villages.

Results: Monthly malaria incidence was over six-fold higher in the irrigated villages than the non-irrigated villages. The number of anopheline breeding habitats was 3.6 times higher in the irrigated villages than the non-irrigated villages and the most common Anopheles mosquito breeding habitats were waterlogged field puddles, leakage pools from irrigation canals and poorly functioning irrigation canals. Larval and adult anopheline densities were seven- and nine-fold higher in the irrigated villages than in the non-irrigated villages, respectively, during the study period. Anopheles arabiensis was the predominant species in the study area. Plasmodium falciparum sporozoite rates of An. arabiensis and Anopheles pharoensis were significantly higher in the irrigated villages than the non-irrigated villages. The annual entomological inoculation rate (EIR) calculated for the irrigated and non-irrigated villages were 34.8 and 0.25 P. falciparum infective bites per person per year, respectively. A strong positive correlation was found between bi-weekly anopheline larval density and canal water releases. Similarly, there was a strong positive correlation between bi-weekly vector density and canal water releases lagged by two weeks. Furthermore, monthly malaria incidence was strongly correlated with monthly vector density lagged by a month in the irrigated villages.
\end{abstract}

Conclusion: The present study revealed that the irrigation schemes resulted in intensified malaria transmission due to poor canal water management. Proper canal water management could reduce vector abundance and malaria transmission in the irrigated villages.

Keywords: Malaria, Irrigation, Canal water management, Anopheline mosquito breeding, Ethiopia

\footnotetext{
* Correspondence: s.kibret@gmail.com

'Ecosystem Management, School of Environmental and Rural Science,

University of New England, Armidale NSW 2351, Australia

Full list of author information is available at the end of the article
} 


\section{Background}

Sub-Saharan Africa uses only 3.9\% of its renewable water resources, and only $6.3 \%$ of its arable land is irrigated [1]. The region is long known for malnutrition and it has been predicted that climate change threatens to increase malnutrition in the region by 14 million by 2020 , with staple food production in many sub-Saharan countries falling by more than 25\% [2]. Alarmed by these threats, several large- and small-scale irrigation schemes are under construction across the region with the goal of ensuring food security and alleviating poverty [3]. However, the negative impact of these emerging irrigation schemes on vector-borne disease, especially malaria - a disease that causes between 300 and 500 million infections and some 655,000 deaths globally each year [4] - has been a huge concern [5].

Development of irrigation schemes in sub-Saharan Africa has been blamed for the increase of malaria risk through creating favourable breeding sites for malaria vector mosquitoes [5-9]. However, water resources development also brings opportunities of cost-effective vector control measures through proper water management to create conditions less favourable for mosquito vector breeding [10-14].

Nevertheless, most studies assessing water management options for malaria vector control in sub-Saharan Africa focus on rice irrigation [7,11,14-18] with limited information on irrigation on other crops. Thus, it is crucial to assess the impact of using proper water management for malaria vector control around different crop irrigation schemes. Understanding how water management could be applied for malaria vector control in different irrigation practices will help devise water management options to mitigate malaria around irrigation schemes in Africa. The present study aims to assess the relationship between irrigation practices and malaria transmission and evaluate water management options to mitigate malaria transmission around irrigation schemes in Central Ethiopia.

\section{Methods}

\section{Study area}

The study was conducted in the Ziway area $\left(8^{\circ} 00^{\prime} \mathrm{N}\right.$, $38^{\circ} 40^{\prime} \mathrm{E}$ ) located $165 \mathrm{~km}$ south of Addis Ababa, the capital of Ethiopia, in the middle of the Ethiopian Rift Valley in Central Ethiopia. The area lies at $1,650 \mathrm{~m}$ above sea level with a semi-arid environment. It receives between 700 and $800 \mathrm{~mm}$ of annual rainfall, with the main rains from June to September and short rains in April and May (National Meteorological Agency, unpublished data). The mean annual temperature is $20{ }^{\circ} \mathrm{C}$. The Ziway area is known for its irrigation practice, which covers an irrigated land of some $205 \mathrm{sq} \mathrm{km}$. The source of water for irrigation is Lake Ziway, located $10-15 \mathrm{~km}$ from the irrigated farmland. The water is pumped using three engineoperated pumps feeding three primary earthly canals. The irrigated area extends to some 65 ha of land, mainly producing maize, corn and onions.

Two irrigated (Abime and Kontella) and two nonirrigated (Washigulla and Telanto) villages were selected for mosquito collection. The irrigated villages, situated within $1 \mathrm{~km}$ radius from the irrigated farms, had a population of 5,342 in 2009. A previous study showed that households using irrigation earn about a five-times higher income (US\$550 per household per month) compared to farming households without irrigation (US\$105 per household per month) [19]. However, despite significant income differences, household expenditure on anti-malarial measures (e.g. bed nets and personal protections) was found to be comparable and generally low in both settings [19]. The explanation for this could be the presence of low knowledge, attitude and practice of malaria vector control measures in the irrigated villages [19]. The non-irrigated (control) villages, with a total population of 4,898, are located some 20-25 km from the irrigation scheme but with similar agrarian socio-economic standards except irrigation practice. In both irrigated and non-irrigated villages, housing is mud walls with thatched or iron roofing. Cattle rearing and mud brick making are common practices in all study villages. Access to health care was comparable in irrigated and non-irrigated study villages - on average one health post for 2,048 and 2,107 people, respectively (District Health Office, unpublished data).

Malaria is the leading public health challenge with an unstable/seasonal trend, peaking between September and December following the major wet season months (June-August) [9]. Plasmodium falciparum is the predominant malaria parasite, causing $70 \%$ of malaria infections, followed by Plasmodium vivax [9,20]. Anopheles arabiensis is the primary malaria vector species while Anopheles pharoensis plays secondary role [9].

\section{Retrospective clinical malaria data collection}

To assess the impact of irrigation on malaria risk, retrospective monthly laboratory-confirmed malaria data were collected from the Ziway Health Centre during the study period (November 2009 - October 2010). A malaria dataset was sorted by village, and type of malaria parasite as confirmed by microscopy. Monthly malaria incidence (cases per 1,000 population per month) was calculated for each village to determine the level of malaria transmission in each village across months of the year.

\section{Mosquito sampling}

Larval and adult mosquitoes were collected fortnightly from the irrigated and non-irrigated study villages between November 2009 and October 2010. At each larval 
sampling, all available potential mosquito breeding habitats such as irrigation canals, canal leakage pools (i.e., pools formed from leaking main canals), irrigated field paddies (water-logging in the field due to over-irrigation and poor drainage canals), mud-brick-making pits, rain pools and other man-made pools, such as water-holding wells were surveyed within a $1 \mathrm{~km}$ radius of each study village using standard dippers $(350 \mathrm{ml})$ [21]. The surface area of each potential mosquito-breeding site was estimated in square metre (sq $\mathrm{m}$ ) and sampling was made at a rate of six dips per sq $\mathrm{m}$ (four dips at the margin and two from the middle). Accordingly, sampling was undertaken proportional to the water surface area [9]. Larval anophelines sampled from each type of breeding habitat were kept in separate vials by direct pipetting. Larvae were killed by gently heating and preserved in $70 \%$ alcohol for later species identification. In the laboratory, preserved anopheline larval samples were counted and individually mounted on microscope slides using gum chloral for species identification based on morphological characteristics [22].

Adult mosquitoes were sampled fortnightly using CDC light traps (Model 512; J W Hock Co, Atlanta, USA) between November 2009 and October 2010. A total of 12 light traps were installed in each study village and operated from 18.00 to 06.30 hours during each sampling night. Half of the light traps were operated indoors and the other half installed outdoors in each of the study villages. Houses were randomly selected for light trap mosquito sampling, but the same houses were used throughout the study period. Each indoor light trap was hung on a wall, with the bulb about $45 \mathrm{~cm}$ above the head of a person sleeping under an untreated bed net [23]. Outdoor light traps were hung on trees at close proximity ( $\sim 50$ to $100 \mathrm{~m}$ ) to open cattle enclosures where some individuals spent the evening. In the field laboratory, anopheline mosquitoes were sorted from adult mosquito captures, counted and further identified into species using morphological characteristics [24]. All female anopheline specimens were kept at room temperature $\left(19-22^{\circ} \mathrm{C}\right)$ at the Addis Ababa University, Biomedical Science Laboratory, for later processing.

\section{Mosquito processing}

The head-thorax portion of each dried female anopheline was subjected to circumsporozoite malaria parasite antigens (P. falciparum and $P$. vivax) detection using enzyme-linked immunosorbent assay (ELISA) [25]. The abdomen portion of fed anophelines were tested for blood meal sources (human $v s$ bovine) using the direct ELISA technique [26].

\section{Environmental variables}

Daily canal water releases were recorded from the three primary canals using water flow measuring probe (Global FP111 Flow Probe, Geo Scientific Ltd, Canada).
The water probe was attached to a digital recorder to download the data to a computer, and the data were then exported to Microsoft Excel for analysis. Mean biweekly canal water discharges were calculated to determine the association with bi-weekly mosquito larval and adult densities. The relationship between bi-weekly vector densities and bi-weekly canal water discharges lagged by 2 weeks was assessed taking into consideration duration of larval development.

\section{Statistical analysis}

Monthly malaria incidence was calculated as the number of laboratory-confirmed malaria cases in a given month among 1,000 population [27]. Anopheles larval density was expressed as the mean number of anopheline larvae per sq $\mathrm{m}$, while adult mosquito density were expressed as the mean number of adult mosquitoes per light trap per night. Malaria incidence, larval and adult mosquito densities were compared between the irrigated and non-irrigated villages using Wilcoxon Signed Ranks Test [28].

The sporozoite infection rate of malaria vector species was calculated as the proportion of mosquitoes positive for Plasmodium sporozoites in the total number of mosquitoes of a species tested by ELISA. The difference in sporozoite rates between the irrigated and non-irrigated villages was analysed by Chi-square test. Man-biting rates were derived from light trap catches (i.e., adult anopheline density divided by a conversion factor 1.5 [23]. A study in northern Ethiopia reported that light traps are 1.5-times (95\% CI $=1.2-1.8)$ more efficient than human landing catches [23]. The sporozoite rate was then multiplied by man-biting rate to determine entomological inoculation rates (EIR). The difference in sporozoite infection rates and annual EIR between the irrigated and non-irrigated villages was analysed by Chi-square test. The human blood index (HBI) for each Anopheles species was calculated as the proportion of samples positive for human blood from the total blood meals of each species tested by blood meal ELISA. Pearson's correlation was employed to test the relationship between bi-weekly canal water releases and bi-weekly anopheline larval/adult densities in the irrigated villages. A similar statistical test was applied to determine the relationship between monthly adult vector density and malaria incidence lagged by one month allowing for mosquito development and the Plasmodium incubation period. The level of significance was determined at 0.05. All analyses were done using Microsoft Excel 2003 and the statistical software, SPSS version 13 (SPSS Inc, Chicago, IL, USA).

\section{Results}

\section{Malaria incidence}

The mean monthly malaria incidence (cases per 1,000 population) was significantly higher in the irrigated villages 
(33.7; 95\% CI $=16.2-51.2 ; \mathrm{z}=-2.431 ; P<0.001)$ compared to the non-irrigated villages $(5.6 ; 95 \% \mathrm{CI}=0.0-11.2)$ (Figure 1 ). In the irrigated villages, bimodal peak in malaria transmission was observed between September and November, and between April and June. The data showed that malaria transmission occurred across all months of the year in the irrigated villages, unlike the non-irrigated villages where transmission occurred mainly during the post-rainy months (September-November) with few or no cases in the dry season. Overall, monthly malaria incidence was over six-fold higher in the irrigated villages than the nonirrigated villages during the study period.

\section{Mosquito breeding and larval abundance}

During the study period, a total of six types of mosquitobreeding habitats (i.e., brick-making pits, rain pools, nonfunctioning canal pools, leakage pools from irrigation canals and agricultural field puddles) were identified (Table 1). While all six types of mosquito-breeding habitats existed in the irrigated villages, only two (brick-making pits and rain pools) were found in the non-irrigated villages. The number of potential mosquito breeding sites was two times higher in the irrigated villages $(n=298)$ than non-irrigated villages $(n=143)$ during the study period. Of these, $53.7 \%$ $(n=160)$ and $34.5 \%(n=45)$ were found positive for larval anopheline mosquitoes in the irrigated and non-irrigated villages, respectively. Agricultural field paddies and leakage pools from irrigation canals contributed over $75 \%$ of larval anopheline-breeding habitats in the irrigated villages while rain pools accounted for over half of the total larval breeding sites in the non-irrigated villages. Overall, there were 3.6 times more anopheline-breeding sites in the irrigated villages than the non-irrigated villages during the study period. Moreover, a total of $68 \mathrm{sq} \mathrm{m}$ of larval anopheline breeding water body was evident in the irrigated villages, compared to only $12 \mathrm{sq} \mathrm{m}$ in the non-irrigated villages during the study period.
A total of 2,959 larval anophelines comprising $A n$. arabiensis, An. pharoensis, Anopheles coustani, and Anopheles funestus were collected during the study period (Table 2). Of these, the majority $(85.5 \% ; n=2,531)$ were collected from the irrigated villages while the remaining $14.5 \%(\mathrm{n}=428)$ were from non-irrigated villages. Anopheles arabiensis was the most common species in all study villages. Larvae of this species were predominantly collected from irrigation-associated breeding sites. Anopheles pharoensis was the second-most abundant species predominantly occurring in agricultural field puddles and leakage pools from irrigation canals. Similarly, larvae of $A n$. coustani and An. funestus were also found in these breeding habitats. In the non-irrigated villages, An. arabiensis was the dominant species, whose larvae were commonly found in rain pools, followed by $A n$. pharoensis and An. coustani. No An. funestus larvae were found in the non-irrigated villages. Overall, the irrigation scheme provided considerable breeding habitats for malaria vector mosquitoes.

Monthly mean Anopheles larval density (mean number of larvae per sq $\mathrm{m}$ ) varied considerably over the study period (Figure 2). A seven-fold higher anopheline larval density was evident in the irrigated villages (mean larval density $=38.0$; 95\% $\mathrm{CI}=21.0-55.0 ; \mathrm{z}=-4.10 ; P<0.001)$ as compared to the non-irrigated villages $(6.7 ; 95 \% \mathrm{CI}=2.1-11.3)$ during the study period. In the irrigated villages, monthly anopheline larval densities were generally higher towards the end of the main rain season (July and September) with a peak in September and a shorter peak in the dry season in March. A similar pattern of monthly anopheline larval density fluctuation was observed in the non-irrigated villages, although larvae disappeared here during the dry season months.

\section{Adult anopheline abundance}

A total of 5,852 adult anophelines were collected using CDC light traps in the study villages (Table 3). Of these, the

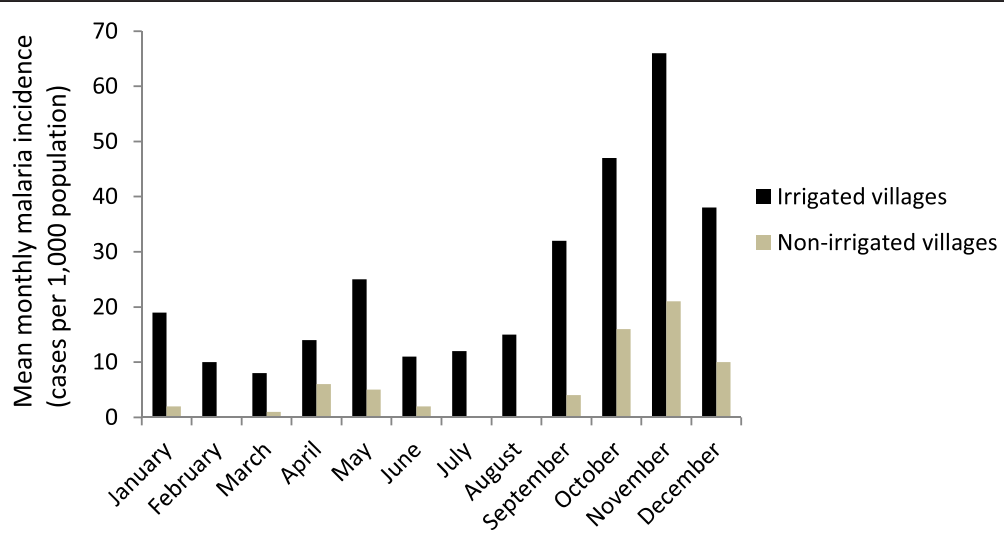

Figure 1 Monthly malaria incidence (cases per 1,000 population) in the irrigated and non-irrigated villages in the Ziway area, Ethiopia, in 2010. 
Table 1 Summary of potential and anopheline larval positive breeding sites in the irrigated and non-irrigated study villages in the Ziway area, Ethiopia, between November 2009 and October 2010

\begin{tabular}{|c|c|c|c|c|c|c|}
\hline \multirow[t]{2}{*}{ Type of larval habitat } & \multicolumn{3}{|c|}{ Irrigated villages } & \multicolumn{3}{|c|}{ Non-irrigated villages } \\
\hline & $\begin{array}{l}\text { No potential } \\
\text { breeding } \\
\text { habitats (\%) }\end{array}$ & $\begin{array}{l}\text { No positive } \\
\text { breeding } \\
\text { sites (\%) }\end{array}$ & $\begin{array}{l}\text { Percentage } \\
\text { of positive } \\
\text { breeding sites }\end{array}$ & $\begin{array}{l}\text { No potential } \\
\text { breeding } \\
\text { sites }(\%)\end{array}$ & $\begin{array}{l}\text { No positive } \\
\text { breeding } \\
\text { sites (\%) }\end{array}$ & $\begin{array}{l}\text { Percentage } \\
\text { of positive } \\
\text { breeding sites }\end{array}$ \\
\hline Brick-making pits & $20(6.7)$ & $9(5.6)$ & $45.0 \%$ & $56(39.2)$ & $21(46.7)$ & $37.5 \%$ \\
\hline Rain pools & $41(13.8)$ & $20(12.5)$ & $48.8 \%$ & $87(60.8)$ & $24(53.3)$ & $27.6 \%$ \\
\hline Non-functioning canal pools & $22(7.4)$ & $10(6.3)$ & $54.4 \%$ & $-\#$ & - & \\
\hline Leakage pools from irrigation canals & $55(18.5)$ & $25(15.6)$ & $45.4 \%$ & - & - & \\
\hline Agricultural field puddles & $160(53.7)$ & $96(60.0)$ & $60.0 \%$ & - & - & \\
\hline Total & $298(100)$ & $160(100)$ & $53.7 \%$ & $143(100)$ & $45(100)$ & $31.5 \%$ \\
\hline
\end{tabular}

\# - these breeding habitats did not exist.

majority (92\%) were collected from the irrigated villages. All four Anopheles species identified in the larval samples were also present in adult collections. Anopheles arabiensis was the predominant species in both irrigated and non-irrigated villages followed by $A n$. pharoensis and An. coustani. Adults of $A n$. funestus were only found in the irrigated villages. The density of adult anophelines (mean number of anophelines per light trap per night) was significantly higher $(P<0.001)$ in the irrigated villages (mean $=19.2$ anophelines/trap/ night; $95 \% \mathrm{CI}=6.1-32.3)$ than the non-irrigated villages (1.9; $95 \% \mathrm{CI}=0.3-3.6)$ throughout the study period.
Adult $A n$. arabiensis densities were significantly higher indoors than outdoors while the other Anopheles species predominantly occurred outdoors.

The monthly densities of $A n$. arabiensis increased remarkably immediately after the long rainy season, between September and October (Figure 3). In contrast, the densities of $A n$. pharoensis increased during the short rainy season with a peak in May. Overall, the densities of malaria vector mosquitoes were substantially higher in the irrigated villages than in the non-irrigated villages throughout the study period.

Table 2 Summary of species composition and density of anopheline larvae in the irrigated and non-irrigated villages in the Ziway area, Ethiopia, between November 2009 and October 2010

\begin{tabular}{|c|c|c|c|c|c|c|}
\hline \multirow[t]{2}{*}{ Types of breeding habitats } & \multirow{2}{*}{$\begin{array}{l}\text { Mean larval } \\
\text { density }^{\mathrm{a}}\end{array}$} & \multicolumn{5}{|c|}{ Type of mosquito larval habitat } \\
\hline & & $\begin{array}{l}\text { An. arabiensis } \\
\text { n (\%) }\end{array}$ & $\begin{array}{l}\text { An. pharoensis } \\
\mathrm{n}(\%)\end{array}$ & $\begin{array}{l}\text { An. coustani } \\
\mathrm{n}(\%)\end{array}$ & $\begin{array}{l}\text { An. funestus } \\
\mathrm{n}(\%)\end{array}$ & $\begin{array}{l}\text { Total } \\
\text { n (\%) }\end{array}$ \\
\hline \multicolumn{7}{|l|}{ Irrigated villages } \\
\hline Brick-making pits & 3.2 & $20(1.5)$ & $16(1.9)$ & $16(5.1)$ & $0(0.0)$ & $52(2.0)$ \\
\hline Leakage pools from irrigation canal & 46.5 & $319(24.5)$ & $280(32.9)$ & $67(21.2)$ & $19(29.2)$ & $685(27.1)$ \\
\hline Non-functioning canal pools & 29.3 & $139(10.7)$ & $57(6.7)$ & $41(13.0)$ & $0(0.0)$ & $237(9.4)$ \\
\hline Rain pools & 12.4 & $292(22.5)$ & $130(15.3)$ & $63(19.9)$ & $0(0.0)$ & $485(19.2)$ \\
\hline Agricultural field puddles & 41.9 & $530(40.8)$ & $367(43.2)$ & $129(40.8)$ & $46(70.8)$ & $1,072(42.3)$ \\
\hline Total (\% from row total) & 38.0 & $1,300(51.3)$ & $850(33.6)$ & $316(12.5)$ & $65(2.6)$ & $2,531(100)$ \\
\hline \multicolumn{7}{|l|}{ Non-irrigated villages } \\
\hline Brick-making pits & 4.1 & $56(20.6)$ & $9(11.5)$ & $8(10.3)$ & $-*$ & $73(17.1)$ \\
\hline Leakage pools from irrigation canal ${ }^{\#}$ & - & - & - & - & - & - \\
\hline Non-functioning canal pools ${ }^{\#}$ & - & - & - & - & - & - \\
\hline Rain pools & 9.3 & $216(79.4)$ & $69(88.5)$ & $70(89.7)$ & - & $355(82.9)$ \\
\hline Agricultural field puddles ${ }^{\#}$ & - & - & - & - & - & - \\
\hline Total (\% from row total) & 6.7 & $272(63.6)$ & $78(18.2)$ & 78 (18.2) & - & $428(100)$ \\
\hline Grand total (\% from row total) & NA & $1572(53.1)$ & $928(31.4)$ & $394(13.3)$ & $65(2.2)$ & $2,959(100)$ \\
\hline
\end{tabular}

${ }^{a}$ mean larval density refers to no. anopheline larvae per sq $\mathrm{m}$.

* - shows this mosquito species was not found in either larval or adult form in these villages.

\# - these mosquito breeding habitats were absent in the non-irrigated villages.

NA - not applicable. 


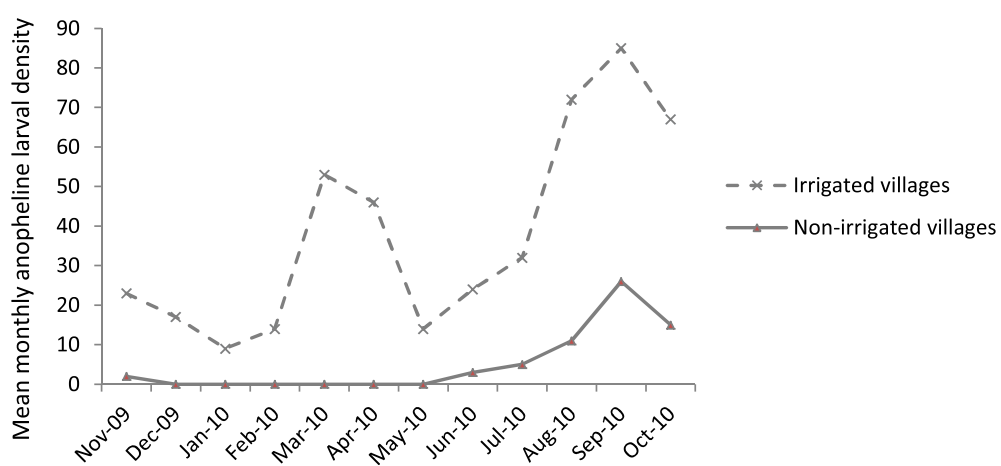

Figure 2 Monthly trend of anopheline larval density (no. larvae per sq $\mathrm{m}$ ) in the irrigated and non-irrigated villages in the Ziway area, Ethiopia, between November 2009 and October 2010.

Source of blood meal and entomological inoculation rate ELISA bioassay results showed that An. arabiensis was the predominant human-blood feeding species with high HBI both in the irrigated (80\%) and non-irrigated villages (73\%) (Table 4). Anopheles pharoensis showed a slight preference for human blood (63.6\%) over bovines (49.5\%) in the irrigated villages, while it fed ambivalently on both humans (59.2\%) and bovines (53.5\%) in the non-irrigated villages. However, the HBI of $A n$. arabiensis $\left(X^{2}=2.12\right.$; degree of freedom $[\mathrm{df}]=1 ; P>0.05)$ and $A n$. pharoensis $\left(X^{2}=3.42 ; \mathrm{df}=1 ; P>0.05\right)$ was not significantly higher in the irrigated villages than the non-irrigated villages. Anopheles coustani primarily fed on bovines in both irrigated (77.6\%) and non-irrigated (72.6\%) villages. Similarly, An. funestus primarily fed on bovines in the irrigated villages.

Plasmodium falciparum sporozoites were detected in An. arabiensis (1.67\%) and An. pharoensis (0.81\%) specimens from the irrigated villages while only one An. arabiensis $(0.43 \%)$ was found to be positive for malaria sporozoites in the non-irrigated villages during the study period (Table 5). In the irrigated villages, $P$. falciparum-positive An. arabiensis specimens were collected in May $(n=2)$, April $(n=3)$, September $(n=16)$, October $(n=9)$, November $(n=4)$,
December $(\mathrm{n}=1)$, indicating active malaria transmission both in dry and wet seasons, while only one An. arabiensis specimen in the non-irrigated villages was found to be positive in September. The annual EIR calculated for the irrigated villages were 27.3 and $7.5 P$. falciparum infective bites per person per year by $A n$. arabiensis and An. pharoensis, respectively. In the non-irrigated villages, the annual EIR for An. arabiensis was 0.25 P. falciparum infective bites per person per year. The difference in EIR between irrigated and non-irrigated villages was significant $\left(X^{2}=12.31 ; \mathrm{df}=1 ; P<0.05\right)$. No $P$. vivax sporpzoites were detected from any of the samples tested in the irrigated and non-irrigated villages.

\section{Impact of canal water release on vector abundance}

Person's correlation analysis revealed that bi-weekly anopheline larval densities were strongly positively correlated $\left(\mathrm{r}^{2}=0.83 ; P<0.05\right)$ with bi-weekly canal water releases in the irrigated study villages (Figure 4). This relationship was linear and it was also noted that one unit increase in canal water release could result in about a ten unit increase in anopheline larval density in the irrigated villages. Furthermore, bi-weekly anopheline larval densities lagged

Table 3 Total number of adult anopheline collected using CDC light traps, and indoor and outdoor adult anopheline densities (mean number adult anophelines per light trap per night) in the irrigated and non-irrigated villages in the Ziway area, Ethiopia, between November 2009 and October 2010

\begin{tabular}{|c|c|c|c|c|c|}
\hline & An. arabiensis & An. pharoensis & An. coustani & An. funestus & Total \\
\hline \multicolumn{6}{|l|}{ Irrigated villages } \\
\hline$N(\%)^{*}$ & $2,945(55)$ & $1,678(31)$ & $569(11)$ & $165(3)$ & $5,357(100)$ \\
\hline No. collected indoors (density) & $1,105(15.33)$ & $698(5.82)$ & $217(1.81)$ & $14(0.12)$ & $2,034(23.08)$ \\
\hline No. collected outdoors (density ${ }^{\#}$ ) & $1,840(9.21)$ & $980(8.17)$ & $352(2.93)$ & $151(1.26)$ & $3,323(21.57)$ \\
\hline \multicolumn{6}{|l|}{ Non-irrigated villages } \\
\hline$N(\%)$ & $321(65)$ & $105(21)$ & $69(11)$ & 0 & $495(100)$ \\
\hline No. collected indoors (density) & $233(1.94)$ & $31(0.26)$ & $22(0.18)$ & 0.00 & $286(2.38)$ \\
\hline No. collected outdoors (density") & $88(0.73)$ & $74(0.62)$ & $47(0.39)$ & 0.00 & $209(1.74)$ \\
\hline
\end{tabular}

*number of adult anophelines collected during the study period (and percentage from row totals).

\#density refers to mean no. anophelines per trap per night. 


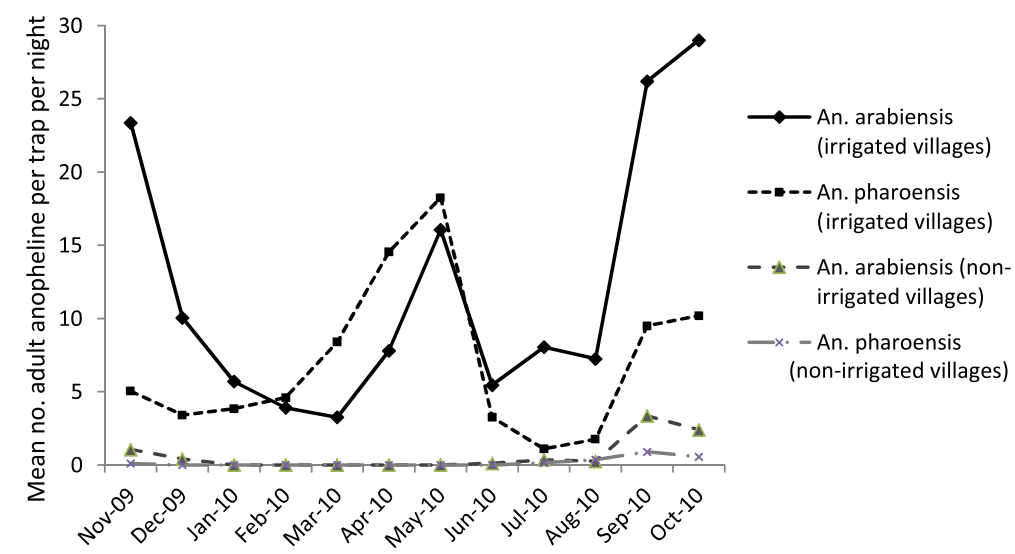

Figure 3 Monthly malaria vector density (mean no. of adult anopheline per light trap per night) in the irrigated and non-irrigated villages in the Ziway area, Ethiopia, between November 2009 and October 2010.

by two week were also positively correlated $\left(\mathrm{r}^{2}=0.62\right.$; $P<0.05)$ with bi-weekly adult anopheline densities in the irrigated villages (Figure 5). Overall, these results indicate the strong link between irrigation-associated larval breeding and vector abundance in the irrigated villages.

In addition, Person's correlation analysis indicated that mean bi-weekly adult anopheline density was positively correlated $\left(\mathrm{r}^{2}=0.53 ; \quad P<0.05\right)$ with mean bi-weekly canal water releases lagged by two weeks in the irrigated villages (Figure 6). Furthermore, the anopheline larval breeding surface area in the irrigated villages $(68 \mathrm{sq} \mathrm{m})$ was four-time larger than the non-irrigated villages (12 sq m) during the study period.

\section{Impact of vector abundance on malaria incidence}

Correlation analysis indicates that monthly malaria incidences (cases per 1,000 population) were significantly correlated $\left(\mathrm{r}^{2}=0.76, P<0.05\right)$ with monthly malaria vector density (i.e., An. arabiensis and An. pharoensis) lagged by one month in the irrigated villages (Figure 7). This implies that higher vector density in any one month was associated with higher malaria incidence in the following month. This suggests that an increase in vector density could lead to an increase to malaria transmission. In contrast, monthly malaria incidence in the non-irrigated villages, was not significantly correlated $\left(\mathrm{r}^{2}=0.21, P>0.05\right)$ with monthly vector densities lagged by one month during the study period.

\section{Discussion}

The present study indicated that the small-scale irrigation schemes of Central Ethiopia resulted in increased malaria transmission in communities living in the irrigated villages throughout most of the year. Irrigation-associated mosquitobreeding habitats (irrigated field puddles, leakages from irrigation canals and non-functional canal pools) were the prominent malaria vector breeding sites throughout the year. The high vector densities of An. arabiensis and

Table 4 Sources of blood meal in female anophelines in the irrigated and non-irrigated villages in the Ziway area, Ethiopia, between November 2009 and October 2010

\begin{tabular}{|c|c|c|c|c|}
\hline & An. arabiensis & An. pharoensis & An. coustani & An. funestus \\
\hline \multicolumn{5}{|l|}{ Irrigated villages } \\
\hline Number tested ${ }^{\mathrm{a}}$ & 2,101 & 992 & 215 & 58 \\
\hline Positive for human blood (\%) & $1,678(80.0)$ & $631(63.6)$ & $107(49.8)$ & $21(36.2)$ \\
\hline Positive for bovine blood (\%) & $593(28.2)$ & $491(49.5)$ & $156(72.6)$ & $45(77.6)$ \\
\hline Unidentified $(\%)^{b}$ & $16(0.8)$ & $21(2.1)$ & $9(4.2)$ & $2(3.4)$ \\
\hline \multicolumn{5}{|l|}{ Non-irrigated villages } \\
\hline Number tested & 234 & 71 & 29 & $-c$ \\
\hline Positive for human blood (\%) & $171(73.1)$ & $42(59.2)$ & $11(37.9)$ & \\
\hline Positive for bovine blood (\%) & $56(23.9)$ & $38(53.5)$ & $23(79.3)$ & - \\
\hline Unidentified (\%) & $13(5.6)$ & $5(7.0)$ & $4(13.8)$ & - \\
\hline
\end{tabular}

${ }^{\mathrm{a}}$ Samples that were positive for both human blood and bovine blood were included in both categories. Hence the total in each row could be more than $100 \%$. bunidentified blood was neither from humans nor from cattle.

${ }^{\mathrm{c}} \mathrm{No}$ An. funestus were collected in the non-irrigated villages. 
Table 5 Plasmodium falciparum sporozoite rates in four Anopheles species collected from the irrigated and non-irrigated villages in the Ziway area, Ethiopia, between November 2009 and October 2010

\begin{tabular}{|c|c|c|c|c|}
\hline & An. arabiensis & An. pharoensis & An. coustani & An. funestus \\
\hline \multicolumn{5}{|l|}{ Irrigated villages } \\
\hline Number tested & 2101 & 992 & 215 & 58 \\
\hline Number positive (\%) & $35(1.67)$ & $8(0.81)$ & $0(0.0)$ & $0(0.0)$ \\
\hline \multicolumn{5}{|l|}{ Non-irrigated villages } \\
\hline Number tested & 234 & 71 & 29 & $-*$ \\
\hline Number positive (\%) & $1(0.43)$ & $0(0.0)$ & $0(0.0)$ & - \\
\hline
\end{tabular}

*No An. funestus were collected in the non-irrigated villages.

An. pharoensis in the irrigated villages coupled with their potential to inoculate 27.3 and 7.5 P. falciparum infective bites per person per year, respectively, confirms the significant risk of malaria transmission in communities living close to the irrigation schemes. Moreover, due to the availability of water for mosquito breeding, the irrigation schemes appear to extend the period of malaria transmission into the dry season in the irrigated villages. These findings were consistent with previous findings elsewhere in Ethiopia [6,9,23,29]. In contrast to the present study findings, rice irrigated villages in the Lower Moshi irrigation scheme in northern Tanzania [30] and the Office du Niger irrigation scheme of Mali [15,31] significantly increased vector densities, but without amplifying the EIR in the irrigated villages, while the EIR rose in the non-irrigated villages. The explanation for the observed higher vector density but a lower EIR in the irrigated villages than the non-irrigated villages was due to lower vectorial capacity as a consequence of amplified vector densities competing for human blood feeding.

Significantly higher monthly malaria prevalence coupled with higher EIR in the irrigated villages than the nonirrigated villages in the present study suggest the risk of malaria transmission in the irrigated villages throughout most of the year. In Western Ethiopia, Jaleta et al. [29] reported a 5.7 -fold higher annual EIR by An. arabiensis in irrigated sugarcane villages than non-irrigated villages. The present study confirmed that dry season malaria transmission was established in the irrigated villages of Central Ethiopia. In tropical Africa where seasonality in rainfall drives the seasonal dynamics of malaria transmission, the presence of irrigation activities has been shown to have a dampening effect on the seasonality of malaria transmission [32]. A previous study indicated that rainfall is the main climatic determinant of seasonal malaria transmission in the Ziway area [33]. Such seasonal transmission is common in the Ethiopian Rift Valley [9,34-36]. However, the present study confirmed that the irrigation schemes in the Ziway area have created conducive conditions for mosquitoes breeding during the dry season and thus the period of malaria transmission is extending throughout most of the year. Significantly higher larval anopheline densities observed in the irrigated villages than in the non-irrigated villages throughout the study period confirms that irrigation drives mosquito abundance. Similar results were previously reported in the same study area [9], Northern Ethiopia [23], and Western Ethiopia [29]. Furthermore, the present study confirmed the presence of malaria

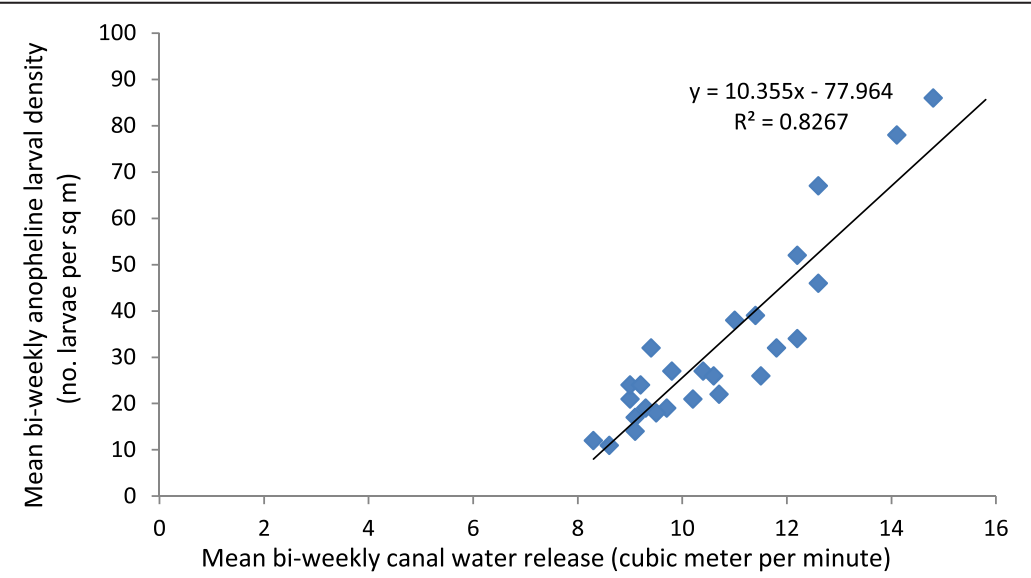

Figure 4 Scatter graph showing a strong positive correlation between mean bi-weekly anopheline larval density and mean bi-weekly canal water release in the irrigated villages in the Ziway area, Ethiopia, between November 2009 and October 2010. 


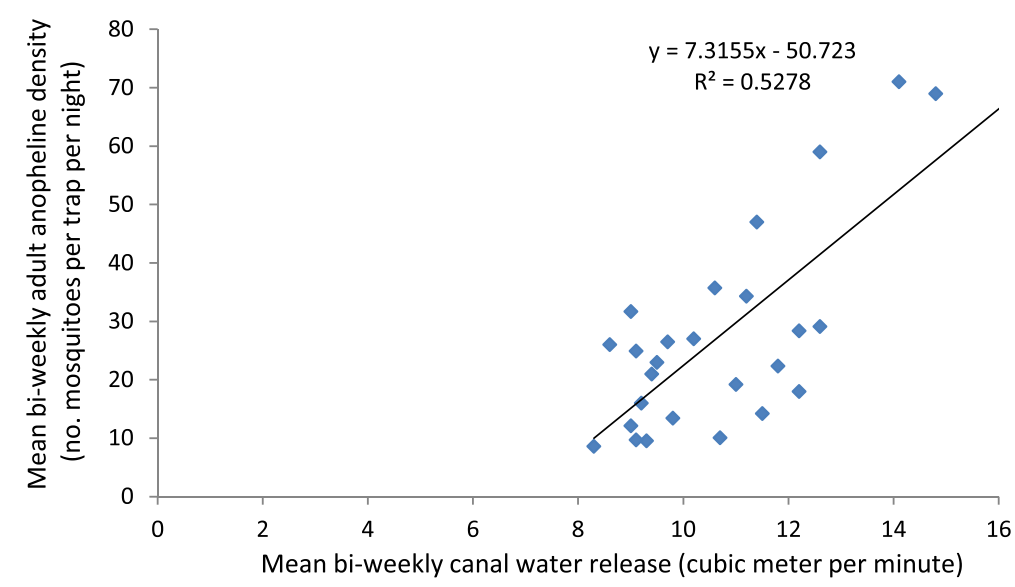

Figure 5 Scatter graph showing a potential positive correlation between bi-weekly adult anopheline density and mean bi-weekly canal water release lagged by 2 weeks in the irrigated villages in the Ziway area, Ethiopia, between November 2009 and October 2010.

sporozoite-infected mosquitoes during the dry season. Similar findings were reported from irrigated sugarcane farms in Western Ethiopia where higher sporozoite rates were observed throughout the months of the year in irrigated villages than the non-irrigated villages [29]. Likewise, irrigation schemes in semi-arid areas of Sahel in Mali were blamed for extending malaria transmission into the dry season [15,37].

Strong positive correlation between canal water release and anopheline larval density coupled with the presence of leakage pools from irrigating canals and water-logged field puddles in the irrigated villages indicate improper canal water management that led to increased malaria vector breeding and thus intensified malaria transmission. This is due to the thriving of the two malaria vector species (An. arabiensis and An. pharoensis) in irrigated fields and seepages created by the irrigation schemes. Similar findings were previously reported for these two malaria vectors from the Ziway area of Ethiopia [9] and the Mwea irrigation scheme of Kenya [38,39]. In the northern Ethiopia, proper environmental management around irrigation microdams was reported to significantly reduce vector density (by 49\%) [23].

The present study indicated that $A n$. arabiensis predominantly feeds indoors while $A n$. pharoensis tends to feed more outdoors than indoors in the study area. Similar findings were reported from the Koka area of Central Ethiopia, some $60 \mathrm{~km}$ north of the present study area [9]. The outdoor feeding habit of these malaria vector species is worrisome as the major vector control measure advocated in Ethiopia is insecticide-treated bed nets, which are largely effective for indoor feeding vectors. Moreover, most farmers in the irrigated villages tend to stay outside working on their farmlands during the early hours of the evening (personal observation), and thus are highly exposed to infective bites from exophagic vector mosquitoes. Studies in Ethiopia indicated that the peak biting activity of these two vector species occurs early in

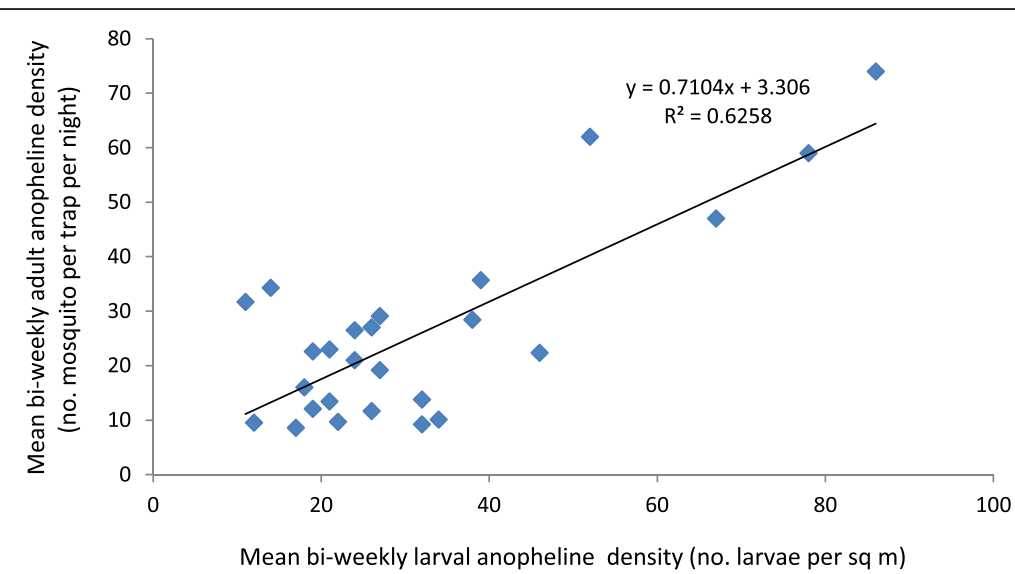

Figure 6 Scatter diagram showing a potential positive correlation between mean bi-weekly larval anopheline density and mean bi-weekly adult anopheline density lagged by 2 weeks in the irrigated villages in the Ziway area, Ethiopia, between November 2009 and October 2010. 


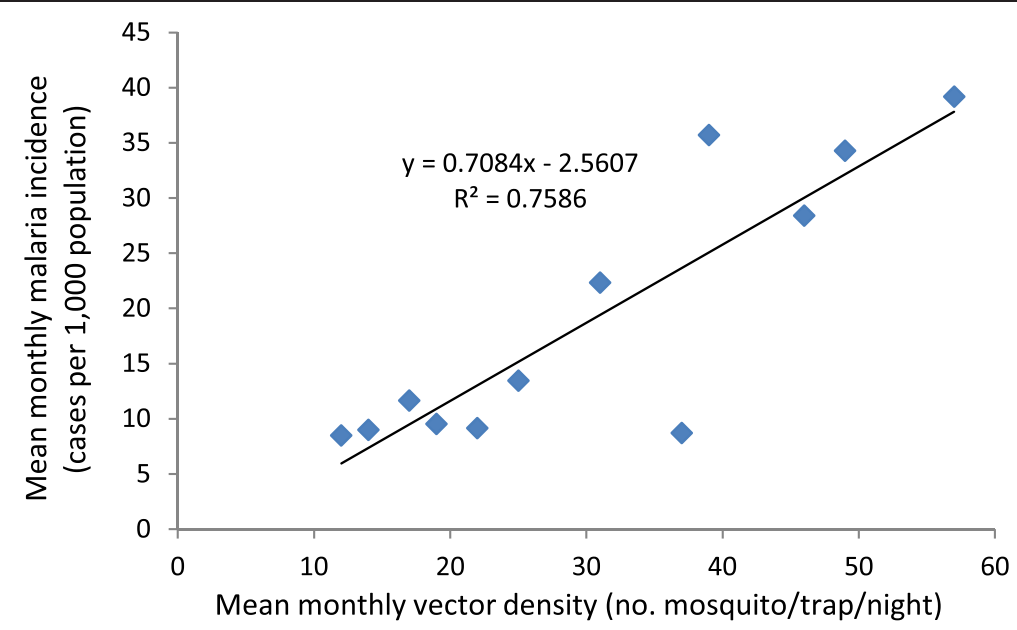

Figure 7 Scatter graph showing a positive correlation between monthly malaria incidence and monthly vector density lagged by one month in the irrigated villages in the Ziway area, Ethiopia, between November 2009 and October 2010.

the evening before people retire to bed, thus compromising the efficacy of bed nets $[9,40]$. This suggests the need for additional vector control measures such as water management options, especially in areas where water resources development schemes are constructed.

The high HBI observed in An. arabiensis both in the irrigated (0.80) and non-irrigated (0.73) villages coupled with the presence of $P$. falciparum sporozoite-infected $A n$. arabiensis reaffirms the important role of this species in malaria transmission in Central Ethiopia. Comparable HBI results were previously documented for this species in the present study area (0.78) [9], in the adjacent Koka area (0.76) [36] and in northern Ethiopia (0.73) [23]. In contrast, lower HBI (0.1-0.5) results were reported for this species in Tanzania [41] and Kenya [17]. This strong zoophilic tendency of $A n$. arabiensis might be the result of differences in species strains and high presence of cattle readily available for mosquito blood meal in these areas. The sporozoite rate (1.67\%) reported for this species in the present study for the irrigated villages was comparable to results from previous studies in same study area (1.18\%) [9]. On the other hand, An. pharoensis $(\mathrm{HBI}=0.64)$ was found predominantly feeding outdoors on human blood with $P$. falciparum sporozoite infection that confirmed its role in malaria transmission. The role of this species in malaria transmission was previously confirmed in Central Ethiopia [9,36]. Anopheles coustani and An. funestus were exophagic and primarily zoophilic with no role in malaria transmission. Similar findings were previously documented from the same study area [20], in the neighbouring Koka area [35] and northern part of Ethiopia [23]. Despite significantly higher vector densities in the irrigated villages, the difference in HBI between the irrigated and non-irrigated villages was not significant. Ijumba and Lindsay [7] pointed out that water resources development projects may cause a shift towards less endophilic and anthropophilic malaria vectors. However, the scope of the present study is too limited to comment on this.

A strong positive correlation between canal water releases and larval/adult vector densities clearly indicates the potential of using canal water management for malaria vector control around irrigation schemes. Mutero et al. [11] found that intermittent irrigation in the Mwea rice irrigation scheme of Kenya resulted in lower mosquito larval densities and survival. The present study indicated that higher canal water releases were associated with higher anopheline larval density, and higher vector abundance in the following fortnight. The two-week lag is explained by the fact that aquatic stages of mosquitoes require at least two weeks (in ambient temperatures, $>21^{\circ} \mathrm{C}$ ) to complete their aquatic life cycle and emerge as adult mosquitoes [42]. As the larval mosquitoes could complete their aquatic development in two-week period, no lag period was applied for bi-weekly canal water releases. The present study found that a unit increase in canal water releases could lead to a ten unit increase in anopheline larval density - suggesting the potential of proper canal water management for malaria vector control. During harvesting months of the year (December - January and May - June), low anopheline larval densities were observed as a consequence of low canal water releases (Figure 2). Furthermore, if proper water management is employed to minimize unwanted water logging, it would substantially reduce vector abundance and hence malaria transmission. Similarly, in the Mwea Irrigation Scheme of Kenya, Muturi et al. [39] suggested that proper water management could reduce vector breeding in irrigation-associated breeding sites, although the authors did not indicate what specific manipulations of the canal releases would bring about low vector breeding. 


\section{Conclusion}

This study revealed that poor canal water management led to a proliferation of malaria vector mosquito breeding sites and intensified malaria transmission in the irrigated villages in Central Ethiopia. Proper canal management by reducing water releases without affecting crop productions (only avoiding unnecessary water logging in the field) during the months of peak malaria transmission could reduce vector abundance and malaria transmission in the irrigated villages. Moreover, health education is needed to encourage irrigators to use personal protections for malaria prevention. The finding that the malaria incidence is associated with adult vector abundance and vector abundance is correlated with larval abundance, which is affected by canal water releases, reaffirms the importance of proper canal water management on malaria transmission. Field experimental studies are needed to further assess how manipulating canal water release could reduce larval and adult vector abundance and hence lower the risk of malaria transmission.

\section{Abbreviations}

CDC: Center for disease control and prevention; ELISA: Enzyme-linked imminosorbant assay; Cl: Confidence interval; DF: Degree of freedom; EIR: Entomological inoculation rate; HBI: Human blood index; US\$: US dollar; WHO: World health organization.

\section{Competing interests}

The authors declare that they have no competing interests.

\section{Authors' contributions}

SK designed the study, conducted the fieldwork and laboratory work, analysed the data and drafted the manuscript. BP was involved during the study conception and design. GGW, HT and BP critically revised the manuscript. All authors read and approved the final manuscript. SK takes the first authorship responsibility.

\section{Acknowledgements}

This study was financially supported by the International Foundation for Science (IFS) grant number W-4752-1. We are grateful to Abime, Kontella, Washigulla and Telanto villagers for allowing us to install light traps inside their households for overnight mosquito collection. We acknowledge the Ziway Health Centre for provision of monthly malaria data. We thank Mr Tesfaye Abebe for field assistance in mosquito collection, and Addis Ababa University for allowing us to use laboratory facilities.

\section{Author details}

${ }^{1}$ Ecosystem Management, School of Environmental and Rural Science, University of New England, Armidale NSW 2351, Australia. ${ }^{2}$ Department of Zoological Sciences, Addis Ababa University, PO Box 1176, Addis Ababa, Ethiopia. ${ }^{3}$ Department Microbial, Cellular and Molecular Biology, Addis Ababa University, PO Box 1176, Addis Ababa, Ethiopia.

Received: 20 June 2014 Accepted: 11 September 2014 Published: 13 September 2014

\section{References}

1. Bank W: The water resources sector strategy: An overview. Washington DC: The World Bank; 2004.

2. Rosegrant MW, Perez ND: Water resources development in Africa: a review and synthesis of issues, potentials, and strategies for the future, EPTD Discussion Paper No. 28. Washington DC: International Food Policy Research Institute; 1997.
3. Hunter JM, Rey L, Chu KY, Adekolu-John EO, Mott KE: Parasitic diseases in water resources development: the need for intersectoral negotiation. Geneva: World Health Organization; 1993.

4. WHO: World Malaria Report 2011. Geneva: World Health Organization; 2012

5. Boelee E, Konradsen F, vander Hoek W (Eds): Malaria in irrigated agriculture: papers and abstracts for the SIMA special seminar at the ICID $18^{\text {th }}$ International congress on irrigation and drainage, Montreal. Colombo: International Water Management Institute; IWMI Working Paper 47; 2002.

6. Ghebreyesus TA, Haile M, Witten KH, Getachew A, Yohannes AM, Yohannes $M$, Teklehaimanot HD, Lindsay SW, Byss P: Incidence of malaria among children living near dams in northern Ethiopia: community based incidence survey. BMJ 1999, 319:663-666.

7. ljumba JN, Lindsay SW: Impact of irrigation on malaria in Africa: paddies paradox. Med Vet Entomol 2001, 15:1-11.

8. Muturi E, Shililu J, Jacob B, Gu W, Githure J, Novak R: Mosquito species diversity and abundance in relation to land use in riceland agroecosystem in Mwea, Kenya. J Vector Biol 2006, 31:129-137.

9. Kibret $S$, Alemu $Y$, Boelee $E$, Tekie $H$, Alemu D, Petros B: The impact of a small-scale irrigation scheme on malaria transmission in Ziway area, Central Ethiopia. Trop Med Int Health 2010, 1:41-50.

10. Utzinger J, Tozan $Y$, Singer BH: Efficacy and cost-effectiveness of environmental management for malaria control. Trop Med Int Health 2001, 9:677-687.

11. Mutero CM, Blank H, Konradsen F, van der Hoek W: Water management for controlling the breeding of Anopheles mosquitoes in rice irrigation schemes in Kenya. Acta Trop 2000, 3:253-63.

12. Keiser J, Caldas de Castro M, Maltese MF, Bos R, Tanner M, Singer BH, Utzinger J: Effect of irrigation and large dams on the burden of malaria on a global and regional scale. Am J Trop Med Hyg 2005, 72:392-406.

13. Walker K, Lynch M: Contributions of Anopheles larval control to malaria suppression in tropical Africa: review of achievements and potential. Med Vet Entomol 2007, 21:2-21.

14. Mwangangi MJ, Shililu J, Muturi EJ, Muriu S, Jacob B, Kabiru EW, Mbogo CM, Githure J, Novak RJ: Anopheles larval abundance and diversity in three rice agro-village complexes Mwea irrigation scheme, central Kenya. Malar J 2010, 9:228.

15. Dolo G, Briet OJT, Dao A, Traore SF, Bouare M, Sogoba N, Niare O, Bagayogo $M$, Sangare $D$, Teuscher T, Toure YT: Malaria transmission in relation to rice cultivation in the irrigated Sahel of Mali. Acta Trop 2004, 89:147-159.

16. Robert V, van de Broek A, Stevens P, Slootweg R, Petrarca V, Coluzzi M, Le Goff G, Di Deco MA, Carnevale P: Mosquitoes and malaria transmission in irrigated rice-fields in the Benoue Valley of northern Cameroon. Acta Trop 1992, 52:201-204.

17. Mutero CM, Kabutha C, Kimani V, Kabuage L, Gitau G, Ssennyonga J, Githure J, Muthami L, Kaida A, Musyoka L, Kiarie E, Oganda M: A transdisciplinary perspective on the links between malaria and agroecosystems in Kenya. Acta Trop 2004, 89:171-186.

18. Keiser J, Utzinger J, Singer BH: The potential of intermittent irrigation for increasing rice yields, lowering water consumption, reducing methane emissions, and controlling malaria in African rice fields. J Am Mosa Control Assoc 2002, 18:329-340.

19. Alemu Y: Irrigation and socio-economic factors related to malaria transmission in Zeway, Eastern Oromia Zone. In MSc Thesis. Ethiopia: Addis Ababa University, Department of Biology; 2007

20. Abose T, Ye-ebiyo Y, Olana D, Alamirew D, Beyene Y, Regassa L, Mengesha A: Reorientation and definition of the role of malaria vector control in Ethiopia. Geneva: WHO/Mal/1998.1085. World Health Organization; 1998:38.

21. Amerasinghe FP, Amerasinghe PH, Peiris JS, Wirtz RA: Anopheline ecology and malaria infection during the irrigation development of an area of the Mahaweli Project, Sri Lanka. Am J Trop Med Hyg 1991, 45:226-235.

22. Verrone G: Outline for the determination of malarial mosquitoes in Ethiopia. Part II. Anopheline larvae. Mosq News 1962, 22:394-401.

23. Yohannes M, Mituku H, Ghebreyesus TA, Witten KH, Getachew A, Byass P, Lindsay SW: Can source reduction of mosquito larval habitat reduce transmission of malaria in Tigray, Ethiopia? Trop Med Int Health 2005, 10:1274-1285

24. Verrone G: Outline for the determination of malarial mosquitoes in Ethiopia. Part I. Adult female anophelines. Mosq News 1962, 22:37-49.

25. Wirtz RA, Zavala F, Charoenvit Y, Campbell GH, Burkot TR, Schneider I, Esser KM, Beaudoin RL, Andre RG: Comparative testing of monoclonal antibodies against Plasmodium falciparum sporozoites for ELISA development. Bull World Health Organ 1987, 65:39-45. 
26. Beier JC, Perkins PV, Wirtz RA, Koros J, Diggs D, Gargian TP, Koech DK: Bloodmeal identification by Enzyme-Linked Immunosorbent Assay (ELISA), tested on Anopheles (Diptera: Culicidae) in Kenya. J Med Entomol 1988, 25:9-16.

27. WHO: Disease surveillance for malaria control: an operational manual. Genève: World Health Organization; 2012.

28. Ott RL, Longnecker M: Statistical Methods and Data Analysis. California: Duxbury; 2001.

29. Jaleta KT, Hill SR, Seyoum E, Balkew M, Gebre-Michael T, Ignell R, Tekie H: Agro-ecosystems impact malaria prevalence: large-scale irrigation drives vector population in western Ethiopia. Malar J 2013, 12:350.

30. Ijumba JN, Mosha FW, Lindsay SW: Malaria transmission risk variations derived from different agricultural practices in an irrigated area of northern Tanzania. Med Vet Entomol 2002, 16:28-38.

31. Diuk-Wasser MA, Toure MB, Dolo G, Bagayoko M, Sogoba N, Traore SF, Manoukis N, Taylor CE: Vector abundance and malaria transmission in rice growing villages in Mali. Am J Trop Med Hyg 2005, 6:725-731.

32. Mabaso ML, Craig M, Ross A, Smith T: Environmental predictors of the seasonality of malaria transmission in Africa: the challenge. Am J Trop Med Hyg 2007, 76:33-38.

33. Abose TA, Hay S, Ochola S, Langi P, Beard B, de Vlas SJ, Cox J: Malaria epidemic early warning and detection in African highlands. Trends Parasitol 2004, 20:400-405.

34. Rishikesh N: Observations on Anopheline Vectors of Malaria in an unsprayed Upland Valley in Ethiopia. Geneva: WHO/MAL/66.554; 1966.

35. Kenea O, Balkew M, Gebre-Michael T: Environmental factors associated with larval habitats of anopheline mosquitoes (Diptera: Culicidae) in irrigation and major drainage areas in the middle course of the Rift Valley, central Ethiopia. J Vector Borne Dis 2011, 48:85-92.

36. Kibret S, Lautze J, Boelee E, McCartney M: How does an Ethiopian dam increase malaria? Entomological determinants around the Koka Reservoir. Trop Med Int Health 2012, 11:1320-1328.

37. Sissoko MS, Dicko A, Briet OJ, Sissoko M, Sagara I, Keita HD, Sogoba M, Rogier C, Toure YT, Doumbo OK: Malaria incidence in relation to rice cultivation in the irrigated Sahel of Mali. Acta Trop 2004, 89:161-170.

38. Ijumba NJ, Mwangi RW, Beier JC: Malaria transmission potential of Anopheles mosquitoes in the Mwea-Tebere irrigation schemes, Kenya. Med Vet Entomol 1990, 4:425-432

39. Muturi EJ, Shililu J, Jacob B, Gu W, Githure J, Novak R: Mosquito species diversity and abundance in relation to land use in a riceland agroecosystem in Mwea, Kenya. J Vector Ecol 2006, 1:129-137.

40. Yohannes $\mathrm{M}$, Boelee $\mathrm{E}$ : Early biting rhythm in the afro-tropical vector of malaria, Anopheles arabiensis, and challenges for its control in Ethiopia. Med Vet Entomol 2012, 26:103-105.

41. Mahande AM, Mosha FW, Mahande JM, Kweka EJ: Role of cattle treated with deltamethrine in areas with a high population of Anopheles arabiensis in Moshi, Northern Tanzania. Malar J 2007, 6:109.

42. Teklehaimanot HD, Lipsitch M, Teklehaimanot A, Schwartz J: Weather-based prediction of Plasmodium falciparum malaria in epidemic-prone regions of Ethiopia I. Patterns of lagged weather effects reflect biological mechanisms. Malar J 2004, 3:41.

doi:10.1186/1475-2875-13-360

Cite this article as: Kibret et al:: Increased malaria transmission around irrigation schemes in Ethiopia and the potential of canal water management for malaria vector control. Malaria Journal 2014 13:360.

\section{Submit your next manuscript to BioMed Central and take full advantage of:}

- Convenient online submission

- Thorough peer review

- No space constraints or color figure charges

- Immediate publication on acceptance

- Inclusion in PubMed, CAS, Scopus and Google Scholar

- Research which is freely available for redistribution

Submit your manuscript at www.biomedcentral.com/submit
C Biomed Central 